\title{
Charcot Ankle Arthropathy in CMT1A Exacerbated by Type 2 Diabetes Mellitus
}

\author{
Natalie E. Parks, Timothy J. Benstead
}

Can. J. Neurol. Sci. 2010; 37: 419-421

Charcot-Marie-Tooth (CMT) disease is a hereditary motor and sensory neuropathy characterized by similar phenotype despite genetic heterogeneity ${ }^{1}$. Charcot-Marie-Tooth type 1A, linked to $\mathrm{a} \sim 1.4 \mathrm{Mb}$ duplication containing the peripheral myelin protein-22 gene on chromosome 17p11.2, accounts for $\sim 50 \%$ of all CMT patients ${ }^{2-6}$. Disease severity varies considerably in CMT1A, however, the prototypical phenotype involves weakness and atrophy of distal limb muscles, distal sensory deficits and diminished deep tendon reflexes with symptoms appearing in childhood ${ }^{7}$. Interestingly, increased motor and sensory impairment is observed in CMT1A patients with diabetes $^{8}$.

Pes cavus, a skeletal deformity resulting from characteristic sparing of foot plantar flexors in combination with early weakness of dorsiflexors, is observed in approximately twothirds of CMT1A patients ${ }^{7}$. In contrast, mutilating foot deformities resulting from prominent distal sensory deficits are not typical of CMT1A, but have been associated with the 2B subtype of CMT disease and can be a feature of the Hereditary Sensory Neuropathies ${ }^{9}$. We present a patient who developed Charcot ankle, a destructive arthritis associated with peripheral sensory neuropathy, as a result of CMT1A augmented by type II diabetes mellitus.

\section{CASE}

This 49-year-old man with type II diabetes mellitus for ten years was initially assessed by neurology for a benign headache. He was noted on examination to have classical findings of CMT disease, though he was unaware of the diagnosis. The patient had bilateral pes cavus and walked with a mild steppage gait, being able to clear his toes when walking without ankle splints. Moderate bilateral weakness of ankle dorsiflexion and eversion was accompanied by diminished patellar and absent Achilles reflexes. Sensory examination revealed diminished proprioception, vibration sense, and pin-prick perception distal to the ankle. The patient recalled experiencing numbness and deformity of both feet since early childhood. In addition, several family members (two maternal uncles, one brother and one maternal nephew) had been diagnosed with CMT disease. His mother had high foot arches, but had not been assessed for CMT.

Motor nerve conduction studies performed on the left median and ulnar nerves revealed a markedly diminished conduction velocity $(18.2 \mathrm{~m} / \mathrm{s}$; normal $>40.0 \mathrm{~m} / \mathrm{s})$ and reduced compound muscle action potentials ( 3.3 and $2.8 \mathrm{mV}$, respectively; normals $>4.0$ and $6.0 \mathrm{mV}$ ). No conduction block was present. No response was elicited following motor nerve conduction studies performed on the left tibial and peroneal nerves (recording over foot muscles) or sensory recordings of the left ulnar, median, and sural nerves. Needle electromyography demonstrated increased insertional activity, small numbers of fibrillations and decreased recruitment with large motor unit potentials in the left anterior tibial, medial gastrocnemius and first dorsal interosseous muscles. Electrodiagnostic studies suggested a severe primarily demyelinating polyneuropathy with accompanying denervation of distal extremity muscles, likely due to secondary axonal degeneration.

Charcot-Marie-Tooth 1A was diagnosed following detection of the characteristic peripheral myelin protein 22 locus duplication on chromosome 17. In this case, the duplication was detected by densitometry measurement of a probe designed to anneal to a diagnostic set of three alleles at the peripheral myelin protein 22 locus and by pulsed field gel electrophoresis.

The peripheral neuropathy proved to be a progressive process. Superimposed diabetic neuropathy was a concern, however, blood glucose was well controlled (7.3-7.5 mmol/L range) with the use of insulin. Within three years of presentation, he had lost all proprioception and vibration sensation distal to the ankles and had lower extremity areflexia. In addition, weakness and sensory deficits had appeared in his hands and neuropathic pain had developed in his legs which he described as "burning, hot sensations". Seven years after diagnosis, age 56, he had upper extremity areflexia, marked wasting of hand intrinsics, and sensory deficits extending both to the elbows and knees. Also noted at the seven year follow-up was a painful deformity of the right ankle.

The right ankle was warm and effused. In addition to his usual symmetric bilateral pes cavus, he had valgus deformity of the right ankle. X-ray indicated degenerative changes at the right ankle joint without evidence of fracture. There was anterior subluxation of the talus relative to the distal tibia and fibula with osseous fragmentation associated with the tibiotalar joint. There was diffuse subchondral sclerosis associated with the ankle joint and osteophyte formation in the vicinity of the medial and lateral malleoli. The degenerative process, suggestive of a neuropathic joint, progressed rapidly over the next three years (Figures A,B,C). The patient developed complete hindfoot dissociation with severe ankle tilt and complete destruction of the talocalcaneal and talocrural joints. In summary, the foot was

From the Department of Medicine, Division of Neurology, Dalhousie University, Halifax, Nova Scotia, Canada.

Received SePtember 17, 2009. Final Revisions Submitted November 6, 2009 Correspondence to: Timothy J. Benstead, Division of Neurology, Halifax Infirmary, QEII Health Sciences Centre, 1796 Summer Street, Rm. 3828, Halifax, Nova Scotia, B3H 3A7, Canada 

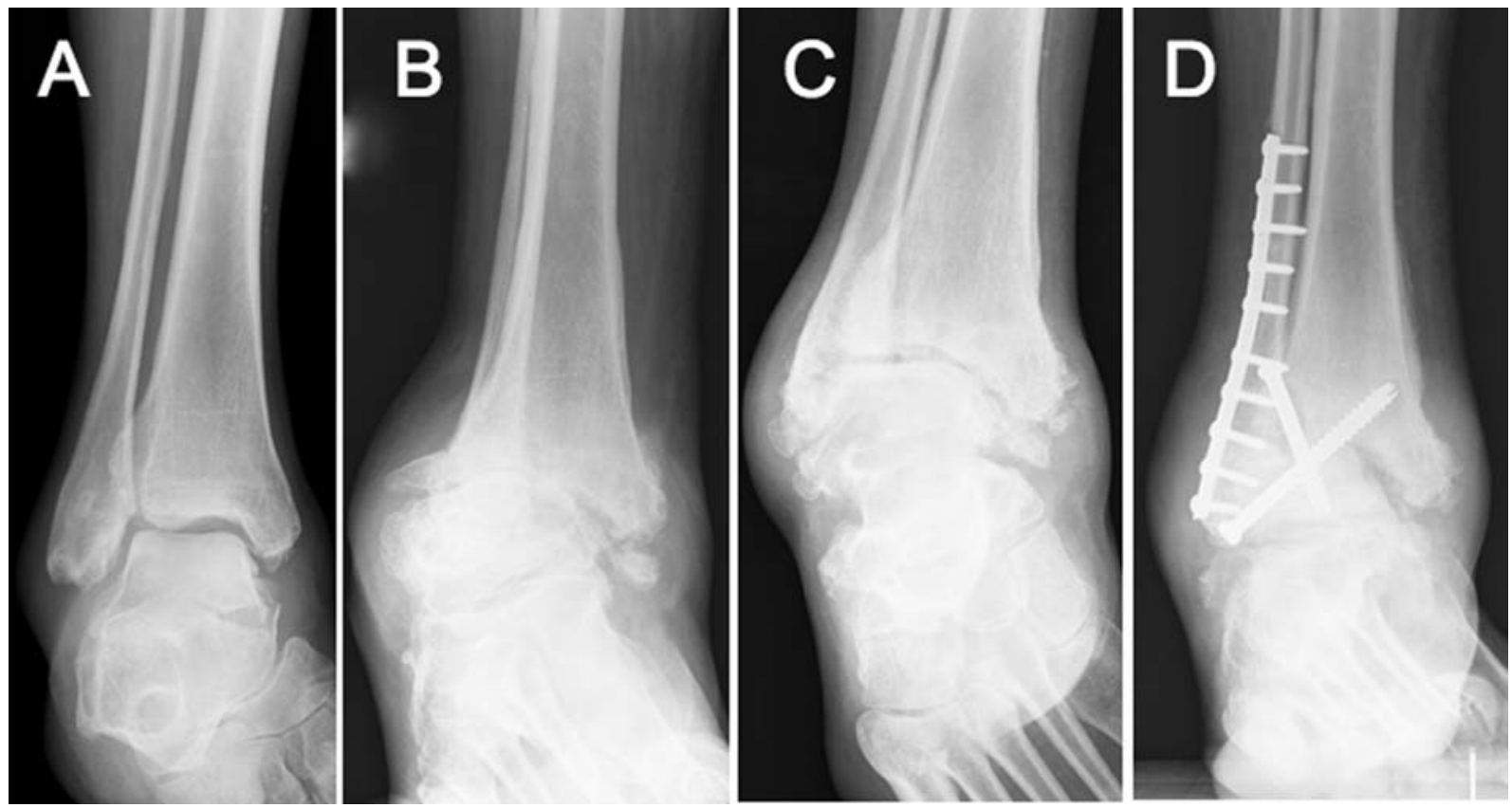

Figure: X-ray images of the right ankle demonstrate progressive degenerative changes due to Charcot arthropathy over a period of three years $(A-C)$. Resultant functional impairment necessitated ankle and subtalar arthrodesis $(D)$.

severely disfigured with a pes cavus midfoot, forefoot claw toes, and hindfoot dissociation. Conservative measures of non-weight bearing and orthotics were unsuccessful and he underwent a right ankle fusion and subtalar fusion, with significant improvement in symptoms (Figure D).

\section{DISCUSSION}

Charcot arthropathy is a destructive arthritis that develops in the context of a peripheral neuropathy involving loss of pain and/or proprioceptive sensation. Characteristic joint changes include degradation of articular cartilage leading to osteosclerosis, osteophyte formation, stress fractures, and erosion of joint surfaces ${ }^{10}$. The condition was first reported in 1703 as an arthropathy associated with advanced venereal disease ${ }^{11}$. Charcot joint is named after Jean-Martin Charcot who described the condition as a complication of tabes dorsalis ${ }^{12}$. Today, diabetes mellitus is the leading cause of a Charcot joint ${ }^{13}$. Though epidemiological data is weak, clinically overt Charcot joint is likely uncommon in large diabetes populations (incidence of 0.2 to $0.3 \%)^{14,15}$, but more frequent in populations of diabetic neuropathy reported from subspecialty clinics and radiologic surveys of patients with diabetic neuropathy ${ }^{16-18}$.

In this patient, it is impossible to differentiate aspects of sensory and motor dysfunction into discrete phenomena caused by diabetic neuropathy versus CMT1A. The development of diabetic neuropathy is strongly suggested by the appearance of "burning" sensations as CMT1A is not usually associated with neuropathic pain ${ }^{7,19}$, though in mixed CMT populations neuropathic pain may be more common ${ }^{20}$. For most of his life this patient had a painless neuropathy typical of CMT1A. As well, the original clinical and electrophysiologic assessments were consistent with moderate expression of the typical CMT1A phenotype with the primary process one of demyelination rather than axonal degeneration, as might be seen in diabetic neuropathy ${ }^{1}$. Therefore, it is unlikely that diabetic neuropathy alone caused the Charcot ankle joint.

Charcot-Marie-Tooth 1A disease expression is highly variable, ranging from asymptomatic to severely affected at a young age, despite linkage of the disorder to an identical $17 \mathrm{p} 11.2$ chromosomal duplication ${ }^{7}$. Additionally, substantial variation in disease severity has been reported between identical twins ${ }^{21}$. This suggests the presence of modifying factors that influence disease phenotype. In patients with apparent severe phenotype from a young age modifier genes are likely necessary to explain variability. However, as additional risk factors for neuropathy arise, a non-genetic modification of the disease can develop ${ }^{22}$. Prior case reports have associated diabetes with severe neuropathy in CMT1A patients ${ }^{23-25}$. In at least one patient foot ulceration has been reported ${ }^{25}$. In a study of ten CMT1A patients with diabetes, neuropathy impairment as measured by the Charcot-Marie-Tooth neuropathy scale was more severe in the diabetic group $(21.3 \pm 6.3)$ compared to age-matched controls with CMT1A alone $(15.9 \pm 4.8)^{8}$. Motor impairment was significantly worse in CMT1A patients with diabetes while a trend toward increased sensory impairment in the diabetes group did not reach significance. The substantial increase in motor impairment is surprising as diabetes alone gives rise typically to a sensory dominated neuropathy.

Mutilating foot deformities, similar to diabetic sequelae, are frequently observed in CMT2B. In this subtype, significant sensory impairment leads to the development of foot ulcers and subsequent infection including osteomyelitis ${ }^{26}$. Other CMT subtypes have rarely been reported to induce deformity related to sensory deficit. Existing accounts are limited to isolated 
instances of CMT1 patients with acrodystrophic skin changes ${ }^{7,9}$, spinal arthropathy secondary to $\mathrm{CMT}^{27}$ and neuropathic ankle joint in two patients with CMT disease following triple arthrodesis for correction of pes cavus ${ }^{28}$. In our case, diabetes may have contributed to the development of a severe CMT1A phenotype manifesting a Charcot foot joint.

The pathogenesis of Charcot joint has not been elucidated, however, neurovascular and neurotraumatic factors may contribute to the phenomenon. The neurovascular theory posits that altered autonomic control of the vasculature leads to increased bone-blood flow, initiating bone resorption and osteopenia $^{29}$. The neurotraumatic theory proposes that insensate joints are subjected to repetitive trauma and extreme ranges of motion which results in inflammation and subsequent bone resorption $^{30}$. While there may be a requirement for traumatic injury to joints prior to the development of Charcot joint, only $22 \%$ of patients recall an injury within one month of symptom onset $^{16,31}$. However, intrinsic muscle weakness due to a motor neuropathy may produce the initiating trauma as resultant eccentric loading of the foot with increased heel and plantar forces induces microfractures ${ }^{32}$.

Significantly increased motor impairment in CMT1A patients with diabetes may contribute to foot instability and subsequent microfractures sufficient to induce a Charcot ankle joint. If this mechanism is correct then this case lends support to the neurotraumatic hypothesis for Charcot joint pathogenesis. Ultimately, this case illustrates that Charcot ankle arthropathy may develop in CMT1A if disease phenotype is modified by the presence of diabetes.

\section{REFERENCES}

1. Pareyson D, Scaioli V, Laura M. Clinical and electrophysiological aspects of Charcot-Marie-Tooth disease. Neuromolecular Med. 2006;8(1-2):3-22.

2. Lupski JR, de Oca-Luna RM, Slaugenhaupt S, Pentao L, Guzzetta V, Trask BJ, et al. DNA duplication associated with CharcotMarie-Tooth disease type 1A. Cell. 1991;66(2):219-32.

3. Raeymaekers P, Timmerman V, Nelis E, De Jonghe P, Hoogendijk JE, Baas F, et al. Duplication in chromosome 17p11.2 in Charcot-Marie-Tooth neuropathy type 1a (CMT 1a). Neuromuscul Disord. 1991;1(2):93-7.

4. Timmerman V, Nelis E, Van Hul W, Nieuwenhuijsen BW, Chen KL, Wang $\mathrm{S}$, et al. The peripheral myelin protein gene PMP-22 is contained within the Charcot-Marie-Tooth disease type 1A duplication. Nat Genet. 1992;1(3):171-5.

5. Nelis E, Van Broeckhoven C, De Jonghe P, Lofgren A, Vandenberghe A, Latour P, et al. Estimation of the mutation frequencies in Charcot-Marie-Tooth disease type 1 and hereditary neuropathy with liability to pressure palsies: a European collaborative study. Eur J Hum Genet. 1996;4(1): 25-33.

6. Wise CA, Garcia CA, Davis SN, Heju Z, Pentao L, Patel PI, et al. Molecular analyses of unrelated Charcot-Marie-Tooth (CMT) disease patients suggest a high frequency of the CMTIA duplication. Am J Hum Genet. 1993;53(4):853-63.

7. Thomas PK, Marques W, Davis MB, Sweeney MG, King RH, Bradley JL, et al. The phenotypic manifestations of chromosome 17p11.2 duplication. Brain. 1997;120(Pt 3):465-78.

8. Sheth S, Francies K, Siskind CE, Feely SM, Lewis RA, Shy ME. Diabetes mellitus exacerbates motor and sensory impairment in CMT1A. J Peripher Nerv Syst. 2008;13(4):299-304.

9. Auer-Grumbach M, De Jonghe P, Verhoeven K, Timmerman V, Wagner K, Hartung HP, et al. Autosomal dominant inherited neuropathies with prominent sensory loss and mutilations: a review. Arch Neurol. 2003;60(3):329-34.
10. Gilliland BC. Relapsing polychondritis and other arthritides. In: Braunwald E, Fauci AS, Kasper DL, Hauser SL, Longo DL, Jameson JL, editors. Harrison's principles of internal medicine, 15e. New York: McGraw-Hill; 2001. p. 2007.

11. Kelly M. De arthritide symptomatica of William Musgrave (16571721): his description of neuropathic arthritis. Bull Hist Med. 1963;37:372-7.

12. Charcot JM. On arthropathies of cerebral or spinal origin. Clin Orthop Relat Res. 1993;296:4-7.

13. Sella EJ, Barrette C. Staging of Charcot neuroarthropathy along the medial column of the foot in the diabetic patient. J Foot Ankle Surg. 1999;38(1):34-40.

14. Sinha S, Munichoodappa CS, Kozak GP. Neuro-arthropathy (Charcot joints) in diabetes mellitus (clinical study of 101 cases). Medicine. 1972;51(3):191-210.

15. Fabrin J, Larsen K, Holstein PE. Long-term follow-up in diabetic Charcot feet with spontaneous onset. Diabetes Care. 2000;23(6): 796-800.

16. Armstrong DG, Todd WF, Lavery LA, Harkless LB, Bushman TR. The natural history of acute Charcot's arthropathy in a diabetic foot specialty clinic. J Am Podiatr Med Assoc. 1997;87(6): 272-8.

17. Cofield RH, Morrison MJ, Beabout JW. Diabetic neuroarthropathy in the foot: patient characteristics and patterns of radiographic change. Foot Ankle. 1983;4(1):15-22.

18. Cavanagh PR, Young MJ, Adams JE, Vickers KL, Boulton AJ. Radiographic abnormalities in the feet of patients with diabetic neuropathy. Diabetes Care. 1994;17(3):201-9.

19. Gemignani F, Melli G, Alfieri S, Inglese C, Marbini A. Sensory manifestations in Charcot-Marie-Tooth disease. J Peripher Nerv Syst. 2004;9(1):7-14.

20. Carter GT, Jensen MP, Galer BS, Kraft GH, Crabtree LD, Beardsley RM, et al. Neuropathic pain in Charcot-Marie-Tooth disease. Arch Phys Med Rehabil. 1998;79(12):1560-4.

21. Garcia CA, Malamut RE, England JD, Parry GS, Liu P, Lupski JR. Clinical variability in two pairs of identical twins with the Charcot-Marie-Tooth disease type 1A duplication. Neurology. 1995;45(11):2090-3

22. Graf WD, Chance PF, Lensch MW, Eng LJ, Lipe HP, Bird TD. Severe vincristine neuropathy in Charcot-Marie-Tooth disease type 1A. Cancer. 1996;77(7):1356-62.

23. Celik M, Forta H, Parman Y, Bissar-Tadmouri N, Demirkirkan K, Battaloglu E. Charcot-Marie-Tooth disease associated with type 2 diabetes mellitus. Diabet Med. 2001;18(8):685-6.

24. Ota T, Osawa K. Marked improvement of glycaemic control with pioglitazone in a type 2 diabetic patient associated with CharcotMarie-Tooth disease. Diabet Med. 2003;20(5):420-1.

25. Thomas PK, King RH, Bradley JL. Hypertrophic neuropathy: atypical appearances resulting from the combination of type I hereditary motor and sensory neuropathy and diabetes mellitus. Neuropathol Appl Neurobiol. 1997;23(4):348-51.

26. Elliott JL, Kwon JM, Goodfellow PJ, Yee WC. Hereditary motor and sensory neuropathy IIB: clinical and electrodiagnostic characteristics. Neurology. 1997;48(1):23-8.

27. Anand N, Levine DB, Burke S, Bansal M. Neuropathic spinal arthropathy in Charcot-Marie-Tooth disease. A case report. J Bone Joint Surg Am. 1997;79(8):1235-9.

28. Medhat MA, Krantz H. Neuropathic ankle joint in Charcot-MarieTooth disease after triple arthrodesis of the foot. Orthop Rev. 1988;17(9):873-80.

29. Brower AC, Allman RM. Pathogenesis of the neurotrophic joint: neurotraumatic vs. neurovascular. Radiology. 1981;139(2): 349-54.

30. Lee L, Blume PA, Sumpio B. Charcot joint disease in diabetes mellitus. Ann Vasc Surg. 2003;17(5):571-80.

31. Eloesser L. On the nature of neuropathic affections of the joints. Ann Surg. 1917;66(2):201-7.

32. Sommer TC, Lee TH. Charcot foot: the diagnostic dilemma. Am Fam Physician. 2001;64(9):1591-8. 